\title{
Tobacco Smoke
}

National Cancer Institute

\section{Source}

National Cancer Institute. Tobacco Smoke. NCI Thesaurus. Code C829.

Smoke from burning tobacco (cig arettes, cigars, or pipes) and exhaled by a smoker.

Tobacco smoke contains nicotine, a stimulant, and other biologically active chemicals having carcinogenic properties. 